\title{
Inventory Model with Demand Rate Is 3-Variables Weibull Function Constant Deterioration, Constant Holding Cost and Inflation without Shortages
}

\author{
Amit Kumar vats ${ }^{1}$, Vijay Singh Rajput ${ }^{2}$, Ranjeet Kaur ${ }^{3}$ \\ ${ }^{1,3}$ (ABES Institute of Technology Ghaziabad) \\ ${ }^{2}$ (OPJS University department of mathematics, Churu, Rajasthan)
}

\begin{abstract}
An inventory model with 3-variable Weibull distribution demand rate and constant deterioration is developed. The holding cost is constant. Shortages are not allowed. The salient feature of this inventory model is for non-perishable products or deteriorating items. A numerical example has been illustrated using MATLAB to describe the model and the sensitivity analysis of various parameters is carried out.
\end{abstract}

Keywords - Constant deterioration; 3-variables Weibull demand; Inflation; Inventory; Constant holding cost

\section{Introduction}

The inventory demand always decreases dependent on time or constant so in the mathematical solution the demand taking with negative singe but some inventory models have declining demand without negative singe in the mathematical solution. In this model used a different declining function 3-variables Weibull distribution. Aggarwal, S. P. (1978) developed a note on an order-level inventory model for a system with constant rate of deterioration. Balkhi,Z. T., et al . (2004) worked on an inventory model for deteriorating items with stock dependent and time-varying demand rates. Benkherouf, L. (1998) discussed note on a deterministic lot size inventory model for deteriorating items with shortages and a declining market. Chakrabarty, T. B., et. al.(1998) developed an EOQ model for items with weibull distribution deterioration, shortages and trended demand: an extension of philip's. Covert, R.B., et al (1973) works on an EOQ model with Weibull distribution deterioration with variable demand. Ghare, P. et al (1963) developed a model for an exponentially decaying inventory. Hariga, M. et al (1994) discussed optimal and heuristic replenishment models for deteriorating items with exponential time varying demand. He, Y., Wang, S., et al.(2010) developed an optimal productioninventory model for deteriorating items with multiple-market demand. Huang W.L. et al (2007) discussed an inventory model for items with weibull distribution deterioration rate under stock-dependent demand and again Huang, Y.F. (2007) developed economic order quantity under conditionally permissible delay in payments. Jalan, A., et al. (1996) worked on the EOQ model for items with weibull distribution deterioration shortages and trended demand. Khanra S. et al (2003) developed a note on an order level inventory model for a deteriorating item with time-dependent quadratic demand. Kun Shan Wu (1998) discussed an Ordering Policy for Items with Weibull distribution Deterioration under permissible Delay in Payments. Mandal, B. (2010) worked on an EOQ inventory model for Weibull distributed deteriorating items under ramp type demand and shortages. Meher, M. K., et al. (2012) developed an Inventory Model with Weibull Deterioration Rate under the Delay in Payment in Demand Decling Market. Philip, G.C. (1974) worked on a generalized EOQ model for items with Weibull distribution. Singh, S.R., et al. (2013a) developed three stage supply chain model with two warehouse, imperfect production, variable demand rate and inflation and again Singh, S.R., (2013b) worked on EOQ Model with Volume Agility, Variable Demand Rate, Weibull Deterioration Rate and Inflation International Journal of Computer Applications 72(.23), 0975 - 8887. Skouri, K., et. al (2009) discussed Inventory models with ramp type demand rate, partial backlogging and weibull deterioration rate. Su, C.T., Lin, et al. (1999) developed a deterministic production inventory model for deteriorating items with an exponential declining demand. Tripathy, C. K., (2010) developed ordering Policy for Weibull Deteriorating Items for Quadratic Demand with Permissible Delay in Payments. T. Singh, et al (2012) Worked on an EOQ Model for A Deteriorating Item with Time Dependent Exponentially Declining Demand Under Permissible Delay In payment Tripathy P.K, (2011) developed an Integrated Partial Backlogging Inventory Model having Weibull Demand and Variable Deterioration rate with the Effect of Trade Credit. Wee, H.M. (1995) discussed joint pricing and replenishment policy for deteriorating inventory with declining market $\mathbf{W u}, \mathbf{O}$. et al (2005) developed an inventory model for deteriorating items with exponential declining demand and partial backlogging. Yadav, R.K et al (2013) worked on volume flexibility in production model with cubic demand rate and weibull deterioration with partial backlogging. Yadav, R. K. et al (2014) developed a deteriorating inventory model for quadratic demand and constant holding cost with partial backlogging and inflation. In this paper discussed in Section 1, we review the literature on the effects of deterioration and time-dependent demand 
rate and we position our model in relative to previous work. Section 2 details the model assumptions. In Section 3 , we have given notation used in model. In Section 4, we formulate the model as a cost minimization problem. In Section 5, a mathematical solution is given to illustrate the model. Section 6details an algorithm for optimizing the solution In Section 7, we sum with a conclusion of this work and suggest directions for future research. Numerical Solution and analysis of various parameters is taken in Section 8.

\section{Assumptions}

The following assumptions are made in developing the model.

$>$ The inventory system considers a single item only.

The demand rate is $\mathbf{3}$-variable Weibull distribution of time.

$>$ The deterioration rate is constant.

$>$ The inventory system is considered over a finite time horizon.

$>$ Lead time is zero.

$>$ Shortages are not allowed.

\section{Notations}

The following notations use for inventory model.

$A: \quad$ Setup cost.

$D(t)$ : $\quad 3$-variable Weibull distribution demand rate in a period $[0, \mathrm{~T}]$

$\theta(t): \quad$ Constant Deterioration rate

Qo : $\quad$ Initial ordering quantity

TD : $\quad$ Total demand in a cycle period $[0, \mathrm{~T}]$

$D U$ : $\quad$ Deteriorating unit in a cycle period $[0, \mathrm{~T}]$

$C_{d}$ : $\quad$ Deteriorating cost per unit

$D C$ : $\quad$ Deteriorating cost

$H C$ : Holding cost

$T C(T)$ : $\quad$ Total inventory cost

$\mathrm{T}^{*}: \quad$ Optimal length size

$Q_{0}^{*}$ : $\quad$ Optimal initial order quantity

$T C^{*}(T): \quad$ Optimal total cost in the period $[0, \mathrm{~T}]$

\section{Mathematical Formulation}

Consider the inventory model of $\mathbf{3}$-variable Weibull distribution demand rate. As the inventory reduces due to demand rate as well as deterioration rate during the interval, the differential representing the inventory status is governed by $[0, \mathrm{~T}]$

$$
\frac{d I(t)}{d t}+\theta I(t)=-D(t), 0 \leq t \leq T
$$

Where $D(t)=\frac{\alpha}{\beta}\left(\frac{t-\mu}{\beta}\right)^{\alpha-1} e^{-\left(\frac{t-\mu}{\beta}\right) \alpha}, D(t) \geq 0, \alpha, \beta \geq 0$

\section{Mathematical Solution}

The solution with boundary condition $I(T)=0$, of the Equation

$\frac{d I(t)}{d t}+\theta I(t)=-\frac{\alpha}{\beta}\left(\frac{t-\mu}{\beta}\right)^{\alpha-1} e^{-\left(\frac{t-\mu}{\beta}\right) \alpha}, 0 \leq t \leq T$ 
$I(t)=-\left\{(1+\theta t)\left[\left(\frac{t-\mu}{\beta}\right)^{\alpha}-\frac{1}{2}\left(\frac{t-\mu}{\beta}\right)^{2 \alpha}\right]+\theta\left[\frac{\beta}{\alpha+1}\left(\frac{t-\mu}{\beta}\right)^{\alpha+1}-\frac{\beta}{2(2 \alpha+1)}\left(\frac{t-\mu}{\beta}\right)^{2 \alpha+1}\right]\right.$

$\left.+(1+\theta T)\left[\left(\frac{T-\mu}{\beta}\right)^{\alpha}-\frac{1}{2}\left(\frac{T-\mu}{\beta}\right)^{2 \alpha}\right]-\theta\left[\frac{\beta}{\alpha+1}\left(\frac{T-\mu}{\beta}\right)^{\alpha+1}-\frac{\beta}{2(2 \alpha+1)}\left(\frac{T-\mu}{\beta}\right)^{2 \alpha+1}\right]\right\} e^{-\theta t}$

Where use the expansion $e^{-x} \approx 1-x+\frac{x^{2}}{2} \ldots, x$ is small and positive.

So the initial order quantity is obtained by putting the boundary condition in Equation (3) $I(0)=Q_{0}$. Therefore,

$$
\begin{aligned}
& Q_{0}=-\left[\left(\frac{-\mu}{\beta}\right)^{\alpha}-\frac{1}{2}\left(\frac{-\mu}{\beta}\right)^{2 \alpha}\right]+\theta\left[\frac{\beta}{\alpha+1}\left(\frac{-\mu}{\beta}\right)^{\alpha+1}-\frac{\beta}{2(2 \alpha+1)}\left(\frac{-\mu}{\beta}\right)^{2 \alpha+1}\right] \\
& +(1+\theta T)\left[\left(\frac{T-\mu}{\beta}\right)^{\alpha}-\frac{1}{2}\left(\frac{T-\mu}{\beta}\right)^{2 \alpha}\right]-\theta\left[\frac{\beta}{\alpha+1}\left(\frac{T-\mu}{\beta}\right)^{\alpha+1}-\frac{\beta}{2(2 \alpha+1)}\left(\frac{T-\mu}{\beta}\right)^{2 \alpha+1}\right]
\end{aligned}
$$

The total demand during the cycle period $[0, \mathrm{~T}]$ is

$$
\begin{aligned}
T D & =\int_{0}^{T} D(t) d t \\
& =\int_{0}^{T} \frac{\alpha}{\beta}\left(\frac{t-\mu}{\beta}\right)^{\alpha-1} e^{-\left(\frac{t-\mu}{\beta}\right) \alpha} d t \\
& =\left[\left(\frac{T-\mu}{\beta}\right)^{\alpha}-\frac{1}{2}\left(\frac{T-\mu}{\beta}\right)^{2 \alpha+1}-\left(\frac{-\mu}{\beta}\right)^{\alpha}-\frac{1}{2}\left(\frac{-\mu}{\beta}\right)^{2 \alpha+1}\right]
\end{aligned}
$$

Then the number of deterioration units is

$$
\begin{aligned}
& D U=Q_{0}-T D \\
& D U=\frac{1}{2}\left(\frac{-\mu}{\beta}\right)^{2 \alpha}+\theta\left[\frac{\beta}{\alpha+1}\left(\frac{-\mu}{\beta}\right)^{\alpha+1}-\frac{\beta}{2(2 \alpha+1)}\left(\frac{-\mu}{\beta}\right)^{2 \alpha+1}\right] \\
& +(1+\theta T)\left[\left(\frac{T-\mu}{\beta}\right)^{\alpha}-\frac{1}{2}\left(\frac{T-\mu}{\beta}\right)^{2 \alpha}\right]-\theta\left[\frac{\beta}{\alpha+1}\left(\frac{T-\mu}{\beta}\right)^{\alpha+1}-\frac{\beta}{2(2 \alpha+1)}\left(\frac{T-\mu}{\beta}\right)^{2 \alpha+1}\right] \\
& -\left[\left(\frac{T-\mu}{\beta}\right)^{\alpha}-\frac{1}{2}\left(\frac{T-\mu}{\beta}\right)^{2 \alpha+1}-\frac{1}{2}\left(\frac{-\mu}{\beta}\right)^{2 \alpha+1}\right]
\end{aligned}
$$

The deterioration cost for the cycle $[0, \mathrm{~T}]$

$D C=C_{d} *$ (Number of deterioration units) 


$$
D C=C_{d} *\left\{\begin{array}{l}
\frac{1}{2}\left(\frac{-\mu}{\beta}\right)^{2 \alpha}+\theta\left[\frac{\beta}{\alpha+1}\left(\frac{-\mu}{\beta}\right)^{\alpha+1}-\frac{\beta}{2(2 \alpha+1)}\left(\frac{-\mu}{\beta}\right)^{2 \alpha+1}\right] \\
+(1+\theta T)\left[\left(\frac{T-\mu}{\beta}\right)^{\alpha}-\frac{1}{2}\left(\frac{T-\mu}{\beta}\right)^{2 \alpha}\right]-\theta\left[\frac{\beta}{\alpha+1}\left(\frac{T-\mu}{\beta}\right)^{\alpha+1}-\frac{\beta}{2(2 \alpha+1)}\left(\frac{T-\mu}{\beta}\right)^{2 \alpha+1}\right] \\
-\left[\left(\frac{T-\mu}{\beta}\right)^{\alpha}-\frac{1}{2}\left(\frac{T-\mu}{\beta}\right)^{2 \alpha+1}-\frac{1}{2}\left(\frac{-\mu}{\beta}\right)^{2 \alpha+1}\right]
\end{array}\right\}
$$

Holding Cost for the cycle $[0, \mathrm{~T}]$ is

$$
H C=\int_{0}^{T} h e^{-r t} I(t) d t
$$

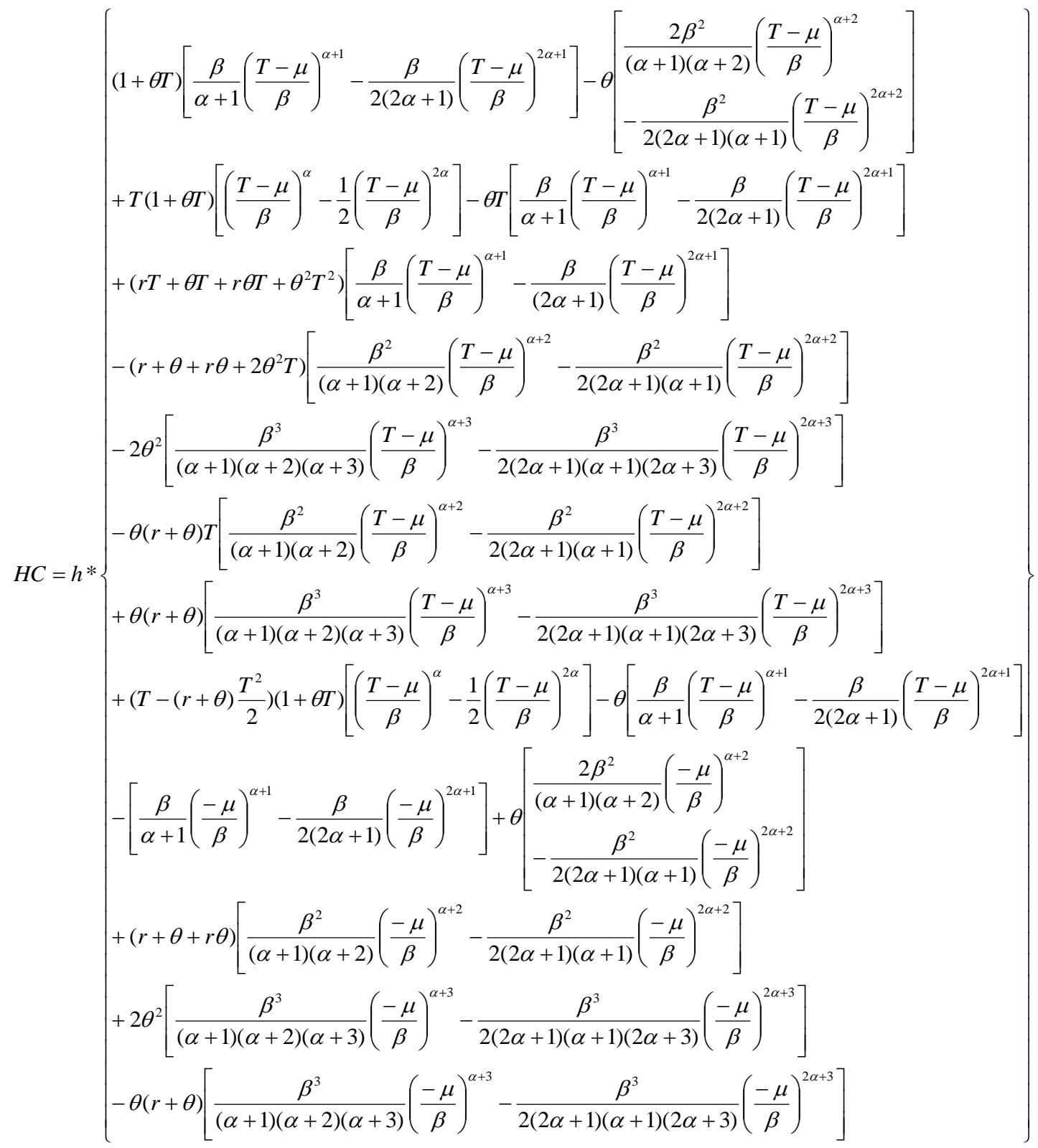


The total inventory cost $\mathrm{TC}(\mathrm{T})=$ Ordering cost $(\mathrm{A})+$ Deterioration cost $(\mathrm{DC})$ + Holding cost $(\mathrm{HC})$

Therefore the total variable cost per unit time

$$
\begin{aligned}
& T C(T)=\frac{1}{T}[A+D C+H C] \\
& T C(T)=\frac{1}{T}\left\{A+C_{d} *\left\{\frac{1}{2}\left(\frac{-\mu}{\beta}\right)^{2 \alpha}+\theta\left[\frac{\beta}{\alpha+1}\left(\frac{-\mu}{\beta}\right)^{\alpha+1}-\frac{\beta}{2(2 \alpha+1)}\left(\frac{-\mu}{\beta}\right)^{2 \alpha+1}\right]\right.\right. \\
& +(1+\theta T)\left[\left(\frac{T-\mu}{\beta}\right)^{\alpha}-\frac{1}{2}\left(\frac{T-\mu}{\beta}\right)^{2 \alpha}\right]-\theta\left[\frac{\beta}{\alpha+1}\left(\frac{T-\mu}{\beta}\right)^{\alpha+1}-\frac{\beta}{2(2 \alpha+1)}\left(\frac{T-\mu}{\beta}\right)^{2 \alpha+1}\right] \\
& \left.-\left[\left(\frac{T-\mu}{\beta}\right)^{\alpha}-\frac{1}{2}\left(\frac{T-\mu}{\beta}\right)^{2 \alpha+1}-\frac{1}{2}\left(\frac{-\mu}{\beta}\right)^{2 \alpha+1}\right]\right\} \\
& +h *\left\{(1+\theta T)\left[\frac{\beta}{\alpha+1}\left(\frac{T-\mu}{\beta}\right)^{\alpha+1}-\frac{\beta}{2(2 \alpha+1)}\left(\frac{T-\mu}{\beta}\right)^{2 \alpha+1}\right]-\theta\left[\begin{array}{c}
\frac{2 \beta^{2}}{(\alpha+1)(\alpha+2)}\left(\frac{T-\mu}{\beta}\right)^{\alpha+2} \\
-\frac{\beta^{2}}{2(2 \alpha+1)(\alpha+1)}\left(\frac{T-\mu}{\beta}\right)^{2 \alpha+2}
\end{array}\right]\right. \\
& +T(1+\theta T)\left[\left(\frac{T-\mu}{\beta}\right)^{\alpha}-\frac{1}{2}\left(\frac{T-\mu}{\beta}\right)^{2 \alpha}\right]-\theta T\left[\frac{\beta}{\alpha+1}\left(\frac{T-\mu}{\beta}\right)^{\alpha+1}-\frac{\beta}{2(2 \alpha+1)}\left(\frac{T-\mu}{\beta}\right)^{2 \alpha+1}\right] \\
& +\left(r T+\theta T+r \theta T+\theta^{2} T^{2}\right)\left[\frac{\beta}{\alpha+1}\left(\frac{T-\mu}{\beta}\right)^{\alpha+1}-\frac{\beta}{(2 \alpha+1)}\left(\frac{T-\mu}{\beta}\right)^{2 \alpha+1}\right] \\
& -\left(r+\theta+r \theta+2 \theta^{2} T\right)\left[\frac{\beta^{2}}{(\alpha+1)(\alpha+2)}\left(\frac{T-\mu}{\beta}\right)^{\alpha+2}-\frac{\beta^{2}}{2(2 \alpha+1)(\alpha+1)}\left(\frac{T-\mu}{\beta}\right)^{2 \alpha+2}\right] \\
& -2 \theta^{2}\left[\frac{\beta^{3}}{(\alpha+1)(\alpha+2)(\alpha+3)}\left(\frac{T-\mu}{\beta}\right)^{\alpha+3}-\frac{\beta^{3}}{2(2 \alpha+1)(\alpha+1)(2 \alpha+3)}\left(\frac{T-\mu}{\beta}\right)^{2 \alpha+3}\right] \\
& -\theta(r+\theta) T\left[\frac{\beta^{2}}{(\alpha+1)(\alpha+2)}\left(\frac{T-\mu}{\beta}\right)^{\alpha+2}-\frac{\beta^{2}}{2(2 \alpha+1)(\alpha+1)}\left(\frac{T-\mu}{\beta}\right)^{2 \alpha+2}\right] \\
& +\theta(r+\theta)\left[\frac{\beta^{3}}{(\alpha+1)(\alpha+2)(\alpha+3)}\left(\frac{T-\mu}{\beta}\right)^{\alpha+3}-\frac{\beta^{3}}{2(2 \alpha+1)(\alpha+1)(2 \alpha+3)}\left(\frac{T-\mu}{\beta}\right)^{2 \alpha+3}\right] \\
& +\left(T-(r+\theta) \frac{T^{2}}{2}\right)(1+\theta T)\left[\left(\frac{T-\mu}{\beta}\right)^{\alpha}-\frac{1}{2}\left(\frac{T-\mu}{\beta}\right)^{2 \alpha}\right]-\theta\left[\frac{\beta}{\alpha+1}\left(\frac{T-\mu}{\beta}\right)^{\alpha+1}-\frac{\beta}{2(2 \alpha+1)}\left(\frac{T-\mu}{\beta}\right)^{2 \alpha+1}\right] \\
& -\left[\frac{\beta}{\alpha+1}\left(\frac{-\mu}{\beta}\right)^{\alpha+1}-\frac{\beta}{2(2 \alpha+1)}\left(\frac{-\mu}{\beta}\right)^{2 \alpha+1}\right]+\theta\left[\begin{array}{l}
\frac{2 \beta^{2}}{(\alpha+1)(\alpha+2)}\left(\frac{-\mu}{\beta}\right)^{\alpha+2} \\
-\frac{\beta^{2}}{2(2 \alpha+1)(\alpha+1)}\left(\frac{-\mu}{\beta}\right)^{2 \alpha+2}
\end{array}\right] \\
& +(r+\theta+r \theta)\left[\frac{\beta^{2}}{(\alpha+1)(\alpha+2)}\left(\frac{-\mu}{\beta}\right)^{\alpha+2}-\frac{\beta^{2}}{2(2 \alpha+1)(\alpha+1)}\left(\frac{-\mu}{\beta}\right)^{2 \alpha+2}\right] \\
& +2 \theta^{2}\left[\frac{\beta^{3}}{(\alpha+1)(\alpha+2)(\alpha+3)}\left(\frac{-\mu}{\beta}\right)^{\alpha+3}-\frac{\beta^{3}}{2(2 \alpha+1)(\alpha+1)(2 \alpha+3)}\left(\frac{-\mu}{\beta}\right)^{2 \alpha+3}\right] \\
& \left.-\theta(r+\theta)\left[\frac{\beta^{3}}{(\alpha+1)(\alpha+2)(\alpha+3)}\left(\frac{-\mu}{\beta}\right)^{\alpha+3}-\frac{\beta^{3}}{2(2 \alpha+1)(\alpha+1)(2 \alpha+3)}\left(\frac{-\mu}{\beta}\right)^{2 \alpha+3}\right]\right\}
\end{aligned}
$$


The necessary and sufficient conditions for minimize cost a given value $T$ are

$$
\frac{d T C(T)}{d T}=0 \text { And } \frac{d^{2} T C(T)}{d T^{2}}>0 \text { then differentiation with respect to } \mathrm{T} \text { of (9), we get }
$$

To find out the solution following algorithm used

\section{Algorithm}

Step1: Find derivative $\frac{d T C(T)}{d T}$ and put $\frac{d T C(T)}{d T}=0$

Step2: Solve equation for $\mathrm{T}$

Step3: Find the derivative $\frac{d^{2} T C(T)}{d T^{2}}$ and check $\frac{d^{2} T C(T)}{d T^{2}}>0$ for $\mathrm{T}^{*}$ optimal length

Step4: Find optimal total cost and initial order quantity

\section{Conclusion}

In the present paper, we developed an inventory model for variable deteriorating item with inflation and the model with 3-variable Weibull distribution demand rate is developed. The deterioration cost is constant. Shortages are not allowed. The model is very practical for the industries in which the demand rate is depending upon the time and holding cost is constant with inflation. This model can further be extended by taking more realistic assumptions such as finite replenishment rate, variable deterioration rate, variable holding etc.

\section{Numerical Solution}

Consider an inventory system with the following parameter in proper units $A=800, \alpha=8$, $\mu=0.6, \beta=3, \theta=0.02, r=0.04, h=10$ and $C_{d}=12$ The computer output of the program by using Mat lab software is $\mathrm{T}^{*}=4.2013, Q_{o}{ }^{*}=182.95$ and $\mathrm{TC}^{*}=343.708$. The effect of changes in the parameter of the inventory model also can be study by using Mat lab. If $\alpha<\beta$ the total cost decreases and if $\mu<\beta$ the total cost is also decreases. If $\alpha$ increases the total cost also decreases but if $r$ increases then total cost increases.

\section{References}

[1] Aggarwal, S. P. (1978). A note on an order-level inventory model for a system with constant rate of deterioration" Journal of the Operational Research Society, Vol. 15, pp. 184-187.

[2] Balkhi,Z. T., and Benkherouf, L. (2004). "On an inventory model for deteriorating items with stock dependent and time-varying demand rates "Computers \& Operations Research, Vol. 31, pp. 223-240.

[3] Tripathy, C. K., and Mishra,U. (2010).“Ordering Policy for Weibull Deteriorating Items for Quadratic Demand with Permissible Delay in Payments" Applied Mathematical Sciences, Vol.4, no.44, 2181-2191.

[4] Chakrabarty, T. B., Giri, C. et. al. (1998). "An EOQ model for items with weibull distribution deterioration, shortages and trended demand: an extension of philip's model [J]," Computers \& Operations Research, Vol. 25, No. 7-8, pp. 649-657.

[5] Covert, R.B., and Philip, G.S. (1973). "An EOQ model with Weibull distribution deterioration” AIIE Transactions, 5 (1973) 323326.

[6] Ghare, P. and Schrader, G. (1963). “A model for an exponentially decaying inventory” Journal of Industrial Engineering,14,238243.

[7] Hariga, M. and Benkherouf, L. (1994). "Optimal and heuristic replenishment models for deteriorating items with exponential time varying demand" European Journal of Operational Research, 79,123-137.

[8] He, Y., Wang, S., et al. (2010). "An optimal production-inventory model for deteriorating items with multiple-market demand" European Journal of Operational Research, 203(3),593-600.

[9] Huang, K.N. and Liao, J.J. (2008). "A simple method to locate the optimal solution for exponentially deteriorating item sunder trade credit financing [J]" Computers and Mathematics with Applications, Vol. 56, No. 4, pp. 965-977.

[10] Huang W.L. and Huang S. (2007). "An inventory model for items with weibull distribution deterioration rate under stockdependent demand [J]" Industrial Engineering and Management, Vol. 2, pp. 72-75,101.

[11] Hwang, H., Shinn, S.W. (1997). Retailer's pricing and lot sizing policy for exponentially deteriorating product under the condition of permissible delay in payments. Computer and Operations Research, Vol. 24, pp. 539-547.

[12] Jalan, A., Giri, R. et al. (1996). "EOQ model for items with weibull distribution deterioration shortages and trended demand" International Journal of System Science Volume- 27, pp-851-855

[13] Khanra S. and K. S. Chaudhuri, (2003). "A note on an order-level inventory model for a deteriorating item with time-dependent quadratic demand" Computers \& Operations Research, Vol. 30, pp. 1901-1916.

[14] Kun Shan Wu (1998). "An Ordering Policy for Items with Weibull distribution Deterioration under permissible Delay in Payments." Tamsui Oxford Journal of Mathematical Science 14 39-54.

[15] Mandal, B. (2010). An EOQ inventory model for Weibull distributed deteriorating items under ramp type demand and shortages. Operation research, 47(2):158-165. 
[16] Meher ,M. K., Panda G.C., et al. (2012). “An Inventory Model with Weibull Deterioration Rate under the Delay in Payment in Demand Decling Market” Applied Mathematical Sciences,Vol.-6, No.23, 1121 -1133.

[17] Philip, G.C. (1974). "A generalized EOQ model for items with Weibull distribution” AIIE Transactions, $6159-162$.

[18] Singh, S.R., Gupta, V. et al. (2013a). Three stage supply chain model with two warehouse, imperfect production, variable demand rate and inflation. International Journal of Industrial Engineering Computations, 4(1), 81-92.

[19] Singh, S.R., Gupta V. (2013b). EOQ Model with Volume Agility, Variable Demand Rate, Weibull Deterioration Rate and Inflation International Journal of Computer Applications 72(.23), 0975 - 8887

[20] Skouri, K.I. Konstantaras, et al. (2007). "Inventory models with ramp type demand rate, partial backlogging and Weibull deterioration rate $[\mathrm{J}]$," European Journal of Operational Research.

[21] Skouri, K., Konstantaras, S. et. al(2009). Inventory models with ramp type demand rate, partial backlogging and weibull deterioration rate. European Journal of Operational Research, 192:79-92.

[22] Su, C.T., Lin, C.W. et al. (1999). "A deterministic production inventory model for deteriorating items with an exponential declining demand" Operational Research Society of India, 36 (2),95-106..

[23] Tripathy P.K, S.Pradhan (2011). "An Integrated Partial Backlogging Inventory Model having Weibull Demand and Variable Deterioration rate with the Effect of Trade Credit." International Journal of Scientific \& Engineering Research Volume 2, Issue 4, ISSN 2229-5518.

[24] Yadav,R.K and Yadav,P. (2013). Volume flexibility in production model with cubic demand rate and weibull deterioration with partial backlogging IOSR Journal of Mathematics 6(4):29-34.

[25] Yadav, R. K. and Vats, A.K. (2014). "A Deteriorating inventory model for quadratic demand and constant holding cost with partial backlogging and inflation” IOSR Journal of Mathematics (IOSR-JM), Vol.10, Issue 3, pp.47-52. 